\title{
Asthma Control in Hospital Tengku Ampuan Afzan, Kuantan, Malaysia: A Cross-sectional Study
}

\author{
Kuan $\mathrm{YC}^{\mathrm{a}}$, Tan $\mathrm{CH}^{\mathrm{b}}$, Hong $\mathrm{CM}^{\mathrm{b}}$, How $\mathrm{SH}^{\mathrm{a}}$ \\ anternational Islamic University Malaysia, Kuantan, Malaysia \\ bHospital Tengku Ampuan Afzan, Kuantan, Malaysia
}

\begin{abstract}
Introduction: Various initiatives and medications have been introduced to achieve better control of bronchial asthma. However total control according to Global Initiative for Asthma (GINA) remains elusive even at tertiary referral hospitals. Our study is to determine the level of asthma control (according to GINA 2009), Asthma Control Test (ACT) scores and the types of medications used among patients with bronchial asthma in a large tertiary hospital. Methods: A cross-sectional study of all patients with bronchial asthma who attended the Chest Clinic at Hospital Tengku Ampuan Afzan (HTAA) from 2009 to 2011. Patient demographics, self-administered ACT scores, GINA-defined level of asthma control and medications were documented. Results: 208 patients were recruited. There were $23.2 \%, 46.3 \%$ and $30.5 \%$ of patients with controlled, partly controlled and uncontrolled asthma respectively. The median ACT scores was 19 [inter quartile range (IQR) 6]. The most frequently used preventer therapy was inhaled long-acting $B$-agonist/corticosteroids (LABA/ICS) fixed-dose combination (61.7\%), and $9.6 \%$ were not on preventer therapy. $75 \%$ of patients with controlled asthma were on LABA/ICS compared to $58.5 \%$ of the partly controlled and uncontrolled groups $(p=0.039)$. Conclusion: The majority of the asthmatic patients attending the Chest Clinic at HTAA did not have GINA-defined controlled asthma. Patients with higher ACT scores had better control of asthma. There were more patients with controlled asthma who were on LABA/ ICS combination.
\end{abstract}

KEYWORDS: Bronchial asthma, level of control, Asthma Control Test

\section{INTRODUCTION}

Bronchial asthma is an age old disease that has been described in the literature since the times of the Greeks and Romans by philosophers, surgeons and prominent physicians such as Avicenna, Maimonides and William Cullen. ${ }^{1}$ It is a disease characterized by recurrent attacks of breathlessness and wheezing, which vary in severity and frequency from person to person. ${ }^{2}$ Treatment has evolved from smoking of datura and "blood-letting"1 to present day inhaler devices.

Besides the familiar metered dose inhalers, other inhaler devices delivering newer and better drugs, the long acting $B$-agonist and inhaled corticosteroid (LABA/ICS) combination in particular, have been introduced into the treatment guidelines of bronchial asthma ${ }^{3}$ to improve the level of asthma control.

Corresponding author:

Dr Kuan Yeh Chunn

Department of Internal Medicine

Kulliyyah of Medicine

International Islamic University Malaysia

Jalan Hospital Campus

25150 Kuantan

Pahang

E-mail: kychunn@yahoo.com

Fax: $+609-5171897$

Tel: $+609-5706000$
The usage of these drugs has increased year by year since its introduction in Hospital Tengku Ampuan Afzan (HTAA), Pahang, Malaysia. HTAA is an 800 bedded hospital and is only one of the two tertiary referral centres under the governance of the Ministry of Health Malaysia in the state of Pahang which has a population of 1.58 million people. In this study, we aimed to determine the level of asthma control as defined by the Global INitiave for Asthma (GINA) ${ }^{3}$ and the Asthma Control Test (ACT) scores in patients with bronchial asthma who were on these inhaled medications. We have obviated peak expiratory flow measurements in our data collection sticking to the principle of a brief, easy to administer, patient-based index of asthma control as described in the development of the ACT.

\section{MATERIALS AND METHODS}

This was a cross-sectional study of all patients aged above 18 years who attended the Chest Clinic in HTAA from 2009 to 2011with at least a year's diagnosis of bronchial asthma and has been on inhaled medications for at least three months. HTAA serves as a tertiary referral centre for respiratory diseases in the state of Pahang.

Patients with a history of other chronic lung diseases such as chronic obstructive pulmonary disease, bronchiectasis and tuberculosis were excluded.

Patient demographics, coexisting atopic conditions 
such as eczema and allergic rhinitis, smoking status, self-administered ACT scores, GINA-defined level of asthma control and their current medications were recorded. Patients who had difficulty completing the ACT had the questionnaire administered by an interviewer.

Analysis was performed using SPSS version 16.0. Categorical data was analysed using Chi-square

Table 1: Patients' characteristics statistical test. Statistical significance was taken at p-value of less than 0.5.

\section{RESULTS}

A total of 208 patients were recruited. The patients' characteristics are shown in Table 1. The majority of the patients were females (74.2\%). The mean duration of asthma was nearly two decades. Two-fifths had claimed to have concomitant allergic rhinitis.

Patients $(\mathrm{N}=208)$

Mean age, years (SD)

$45.4(15.2)$

Sex, \% female

Mean asthma duration, years (SD)

Allergic rhinitis, \%

42.6

Eczema, \%

Current smoker, \%

Pregnant, \%

Overall median ACT scores was 19 [inter quartile range (IQR) 6]. Among patients with controlled, partly controlled and uncontrolled asthma, ACT scores ranged from 15 to 25 (median 22, IQR 4), 10 to 25 (median 20,
IQR 4), and 5 to 23 (median 15, IQR 7) respectively. The median ACT scores were significantly different between asthma control groups ( $p<0.01)$ (Figure 1$)$.

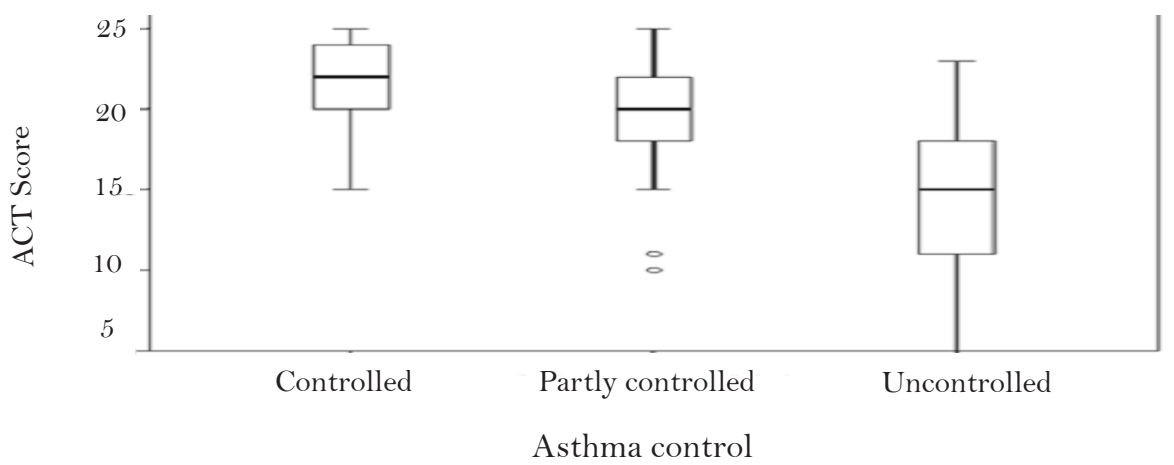

Figure 1: ACT scores and asthma control

The most frequently used preventer therapy was inhaled long-acting B-agonist/corticosteroids (LABA/ICS) fixeddose combination $(61.7 \%)$, followed by budesonide (26.8\%), ciclesonide $(1.4 \%)$ and beclomethasone $(0.5 \%)$ while $9.6 \%$ were not on preventer therapy (Figure 2). $75 \%$ of patients with controlled asthma were on LABA/ ICS compared to $58.5 \%$ of the partly controlled and uncontrolled groups $(p=0.039)$ (Figure 3). 


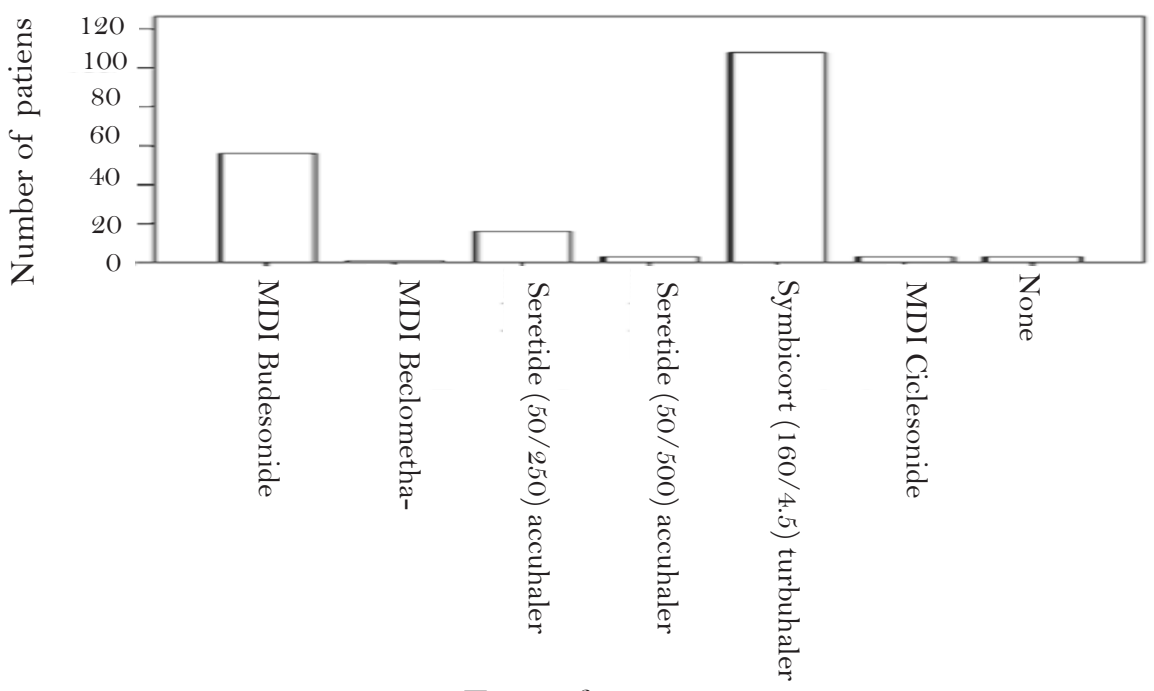

Types of preventer

Figure 2: Types of preventer therapy used by the patients

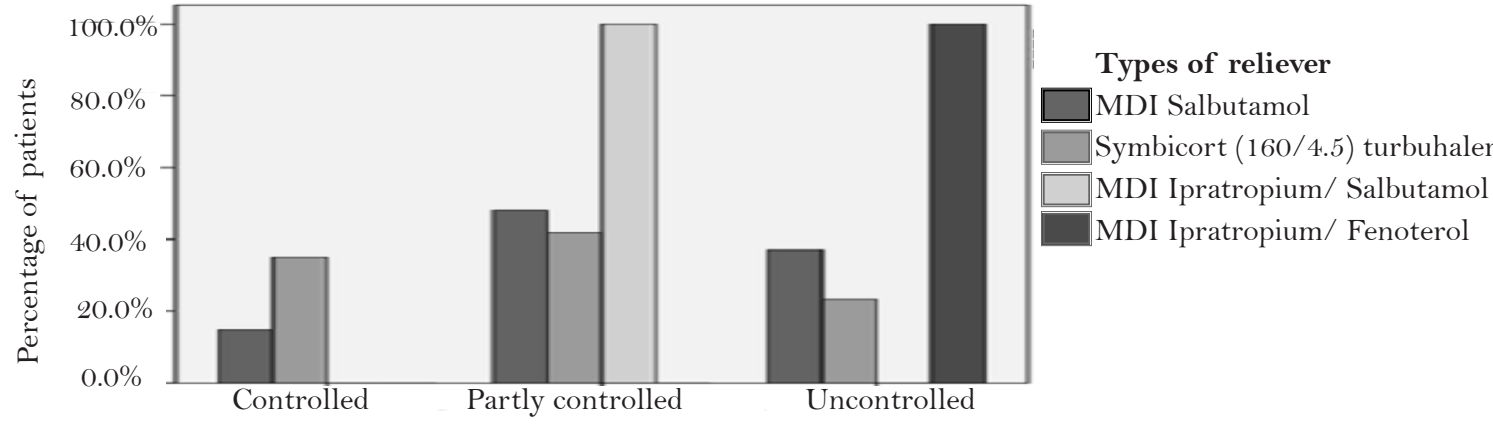

Asthma control

Figure 3: Asthma control and inhaler therapy

\section{DISCUSSION}

Despite advances in its treatment, the control of asthma remains the holy grail of modern day respiratory physicians. When pit against the aspirations of the internationally recognized GINA (Global INitiative for Asthma) guideline, the reality of asthma control falls remarkably short. ${ }^{4-7}$ The AIRIAP and AIRIAP 2 studies $^{8-9}$ which included Malaysia as one of the countries surveyed concluded that the level of asthma control in children and adults in the Asia Pacific region was suboptimal.

The benefit of ICS in the treatment of bronchial asthma cannot be overemphasized. Together with the introduction of LABA to ICS as a fixed combination for maintenance therapy, there has been a profound effect in mortality reduction. ${ }^{10-12}$ Suffice to say that $90 \%$ of our patients were on preventer (either ICS or LABA/ICS fixed combination) therapy while $58.5 \%$ of the partly controlled and uncontrolled groups were on LABA/ICS fixed combination therapy, which is a far cry from the $13 \%$ and $21 \%$ of the partly controlled and uncontrolled groups of patients in the AIRIAP studies. $^{8-9}$ The complexity of the bronchial asthma treatment guidelines which cannot be fully accessed, understood and implemented in time-limited general practice clinics may account for the lower prescription of ICS or LABA/ICS to asthma patients whereas in specialized respiratory clinics, resources and time are not spared in identifying poorly controlled asthma patients and helping them to achieve optimal control with adequate counseling, support and medications.

Although a high proportion of the patients in our study were on preventer therapy, the proportion of patients with well controlled asthma was a dismal $23.2 \%$. Asthma control does not rely solely on prescription of medications but also on other factors such as compliance, technique, inhaler devices, concomitant illnesses, smoking, vaccination, environment, allergen exposure and others which are addressed in the GINA guideline. ${ }^{3}$ With this in mind, clinicians ought to adopt a holistic approach when treating patients with poorly controlled asthma.

In busy clinics, the Asthma Control Test (ACT) is a 
useful tool to quickly assess the patient's asthma control and recognize problematic areas which are preventing the patient from achieving optimal level of control. ${ }^{13}$ In the development study, the ACT scale scores have been validated to discriminate between differing groups of asthma control and the need for change in patients' treatment. A similar result was demonstrated in our study where the ACT scores were significantly different between different levels of GINA defined asthma control. Since the ACT can be selfadministered, it would not be unreasonable to request that patients complete it while waiting to see the doctor and this in turn will conserve considerable amount of consultation time.

\section{CONCLUSION}

Majority of the asthma patients attending the Chest Clinic at HTAA did not have GINA-defined controlled asthma. The patients who had higher ACT scores also had better control of asthma. There were more patients with controlled asthma who were on LABA/ ICS.

\section{REFERENCES}

1. Stolkind $\mathrm{E}$. The history of bronchial asthma and allergy. Proc R Soc Med 1993; 26:1120-1126.

2. From Chronic Respiratory Diseases Asthma: Definition, World Health Organization 2015. Available from http://www.who.int/respiratory/ asthma/definition/en/

3. From the Global Strategy for Asthma Management and Prevention, Global Initiative for Asthma (GINA) 2014. Available from: http: / / www.ginasthma.org/.

4. Barnes PJ. Asthma guidelines: recommendations versus reality. Respir Med 2004;98 Suppl A:S1-7.

5. Crim C. Clinical practice guidelines vs actual clinical practice: the asthma paradigm. Chest 2000;118:62S-4S.

6. Legorreta AP, Christian-Herman J, O'Connor RD, Hasan MM, Evans R, Leung KM. Compliance with national asthma management guidelines and specialty care: a health maintenance organization experience. Arch Intern Med 1998;158:457-64.

7. de Marco R, Cazzoletti L, Cerveri I, Corsico A, Bugiani M, Accordini S, et al. Are the asthma guideline goals achieved in daily practice? A population-based study on treatment adequacy and the control of asthma. Int Arch Allergy Immunol 2005;138:225-34.

8. Lai CK, De Guia TS, Kim YY, et al. Asthma control in the Asia-Pacific region: the Asthma Insights and Reality in Asia-Pacific Study. J Allergy Clin Immunol 2003;111: 263-8.

9. Wong GW, Kwon N, Hong JG, Hsu JY, Gunasekera
KD. Pediatric asthma control in Asia: phase 2 of the Asthma Insights and Reality in Asia-Pacific (AIRIAP 2) survey. Allergy 2013; 68:524-30.

10. Suissa S, Ernst P, Benayoun S, Baltzan M, Cai B. Low-dose inhaled corticosteroids and the prevention of death from asthma. N Engl J Med 2000; 343:332-6.

11. Lanes SF, Garcia Rodriguez LA, Huerta C. Respiratory medications and risk of asthma death. Thorax 2002; 57:683-6.

12. Neffen $H$, Baena-Cagnani C, Passalacqua $G$, Canonica GW, Rocco D. Asthma mortality, inhaled steroids, and changing asthma therapy in Argentina (1990-1999). Respir Med 2006; 100:1431-5.

13. Nathan RA, Sorkness CA, Kosinski M, Schatz M, Li JT, Marcus P, Murray JJ, Pendergraft TB. Development of the asthma control test: a survey for assessing asthma control. J Allergy Clin Immunol. 2004; 113:59-65. 